\title{
A novel technique using the Hendrickx centrifuge for extracting winter sporangia of Synchytrium endobioticum from soil
}

\author{
J. G. N. Wander - W. van den Berg • P. H. J. F. van den Boogert \\ J. G. Lamers - G. C. M. van Leeuwen - G. Hendrickx · P. Bonants
}

Accepted: 26 April 2007/Published online: 5 June 2007

(C) KNPV 2007

\begin{abstract}
A zonal centrifugation method, known as the Hendrickx centrifuge technique, was tested for routine detection of winter sporangia of Synchytrium endobioticum in soil. In four experiments the ability of the Hendrickx centrifuge to extract the sporangia from soil was compared with a method used by the Dutch Plant Protection Service, which is a modification of the recommended EPPO method. Naturally
\end{abstract}

J. G. N. Wander · W. van den Berg · J. G. Lamers ( $₫)$ Applied Plant Research, Wageningen University and Research, P.O. Box 430, Lelystad 8200 AK,

The Netherlands

e-mail: jan.lamers@wur.nl

P. H. J. F. van den Boogert · P. Bonants

Plant Research International BV, Wageningen University and Research, P.O. Box 16, Wageningen 6700 AA,

The Netherlands

P. H. J. F. van den Boogert · G. C. M. van Leeuwen Plant Protection Service, Ministry of Agriculture, Nature and Food Quality, P.O. Box 9102, Wageningen 6700 HC, The Netherlands

G. Hendrickx

Department of Crop Protection, Agricultural Research Centre, Burg. Van Gansberghelaan 96, Merelbeke 9820, Belgium

Present Address:

J. G. N. Wander

DLV Facet, De Drieslag 25, Dronten $8251 \mathrm{JZ}$,

The Netherlands and artificially contaminated soil samples were used to study the recovery percentage of and variation in numbers of winter sporangia. The effects of soil type and inoculum density were studied. The Hendrickx centrifuge method, developed originally for extraction of free living nematodes from soil, performed better than the method used by the Dutch Plant Protection Service. This was due to a better extraction recovery (60\% higher), a lower measurement error (50\% lower) and a lower detection level (down to 0.02 sporangia $\mathrm{g}^{-1}$ soil). The Hendrickx centrifuge method is much less labour-intensive than the method used by the Dutch Plant Protection Service. It can be used to extract many different organisms from soil, and DNA can be subsequently extracted from the supernatant for further PCR analysis. Inclusion of the Hendrickx centrifuge method in the official EPPO diagnostic protocol for regulated pests is recommended as an alternative method for detection of sporangia in soil.

Keywords Detection method - Fungal resting spores - Extraction - Nematodes · PCR test - Wart disease

\section{Introduction}

Synchytrium endobioticum is the causal agent of wart disease of potato (Solanum tuberosum). Potato wart disease occurs in countries with a moderate climate 
and has been reported from India (Singh and Garg, 2003), Russia (Vasyutin and Smetnik, 1999), Ukraine (Zelya and Melnik, 1998), Peru, China (Hampson, 1989), Canada and Europe (Hampson, 1979; Hampson et al., 1983; Baayen et al., 2006). Synchytrium endobioticum is an EPPO A2 quarantine pest, and is listed as an Annex I/AII quarantine pest by the European Union (EU, 2000). Many methods have been developed to extract sporangia of S. endobioticum from soil (Pratt, 1976; Laidlaw, 1985; Stachewicz, 2004). Currently, the method of Pratt (1976) is recommended by EPPO (OEPP/EPPO, 1999). This method consists of wet sieving a soil sample of $100 \mathrm{~g}$ with an electronic sieve shaker, drying the sediment on filter paper, and after dissolving the material centrifuging three times with chloroform or $\mathrm{CaCl}_{2}$, collecting on filter paper and resuspending in lactoglycerol for counting under the microscope. It has the disadvantage that organic matter is not removed from the sample which makes counting difficult (Van Leeuwen et al., 2005).

New outbreaks of $S$. endobioticum occurred in the 1980 s in the Netherlands. Subsequently a new method was developed and implemented by the Dutch Plant Protection Service (PPS-method) (Van Leeuwen et al., 2005). This method was a modification of the method of Pratt (1976), in which a soil sample of $20 \mathrm{~g}$ was used, carcinogenic chloroform was replaced by calcium chloride for centrifugation, and counting in lactoglycerol was replaced by counting in calcium chloride. These methods are laborious and not suitable for routine, high-throughput analysis.

In several trials the PPS-method was compared with the zonal centrifuge technique, which was developed for extraction of free-living nematodes (Hendrickx, 1995). Major differences of the zonal centrifuge technique compared with the PPS-method are: automatic operation, the stepwise addition of materials to the centrifuge rotor and a one step extraction. This method showed a good recovery efficacy for the root knot nematode Meloidogyne chitwoodi (Chen et al., 2000). Results of trials with a prototype of the zonal centrifuge to extract sporangia of $S$. endobioticum were promising. Therefore in order to provide a less laborious automatic method to extract $S$. endobioticum and other structures routinely, the first full-scale Hendrickx centrifuge was built.
The objective of the research was to study the extraction efficiency for $S$. endobioticum with the zonal centrifugation technique and compare it with the EPPO-method and the PPS-method. Results of the comparison between the EPPO-method and the PPSmethod were described by Van Leeuwen et al, (2005). This study focuses on the comparison between the PPS-method and the zonal centrifuge technique. Procedures to handle the Hendrickx centrifuge were optimized, the equipment validated and the recovery, reliability and detection threshold were compared with the PPS-method. The effect of different separation liquids and soil types on percent recovery and variation from the number of winter sporangia added to samples was also investigated for these two methods.

\section{Materials and methods}

In four experiments the Hendrickx centrifuge method (HC-method) was compared with the PPS-method. Experiments 1 and 2 were designed to test the two methods for extracting $S$. endobioticum from soil. Experiment 3 was set up to study the effects of different separation liquids and inoculum densities on the extraction efficiency of the two methods. Experiment 4 was designed to test effects of different soil types with varying inoculum densities on the extraction efficiency of the two methods. The latter two experiments were used to provide material for the PCR assays reported by Van den Boogert et al., (2005).

Extraction methods and counting procedure

In all four experiments the PPS-method and the Hendrickx centrifuge method were compared with each other. The PPS-method (Van Leeuwen et al., 2005) is a modification made by the Dutch Plant Protection Service of the extraction method described in EPPO procedure PM 3/59 (OEPP/EPPO, 1999) which is based on the method of Pratt (1976). In this method the major steps to be taken are: wet sieving, centrifugation with water, and centrifugation of sediment with separation liquid e.g. saturated $\mathrm{CaCl}_{2}$ solution.

The PLC-controlled (Programmable Logic Controllers) Hendrickx centrifuge (HC-method) is based 
on zonal centrifugation. After mixing a 11 suspension of tap water and at most $200 \mathrm{~g}$ soil, the following are automatically added (in order) to the centrifuge rotor rotating horizontally at $15,000 \mathrm{~g}$ : (1) separation liquid, (2) water, (3) 100 to $500 \mathrm{ml}$ soil suspension (see Table 1 for details) and (4) kaolin suspension (see Fig. 1). The separation liquid must have a certain specific gravity which during centrifugation separates particles with a lower and a higher specific gravity. During the centrifugation process the mineral fraction passes through the water and separation liquid and is collected onto the wall of the rotor. Particles with a specific gravity lower than the separation liquid but higher than that of water are retained on the interface between the water ring and the separation liquid. Particles in the suspension with a specific gravity less than that of water (e.g. organic matter) flow out of the centrifuge with the excess of water. At the end of the centrifugation, a thin layer of kaolin seals the sediment. Supernatant of water and $\mathrm{CaCl}_{2}$ solution containing the sporangia is collected in a small beaker through the hollow shaft of the rotor. The supernatant has a specific gravity of about 1.02. Rotor and tubing are automatically cleaned after each sample. The entire process from sample supply to removal of sporangial suspension is automated. Experiments 1 and 2 were carried out with a prototype (HC1-method) built by the Centrum voor Landbouwkundig Onderzoek - Gent, Merelbeke, Belgium. Experiments 3 and 4 were carried out with

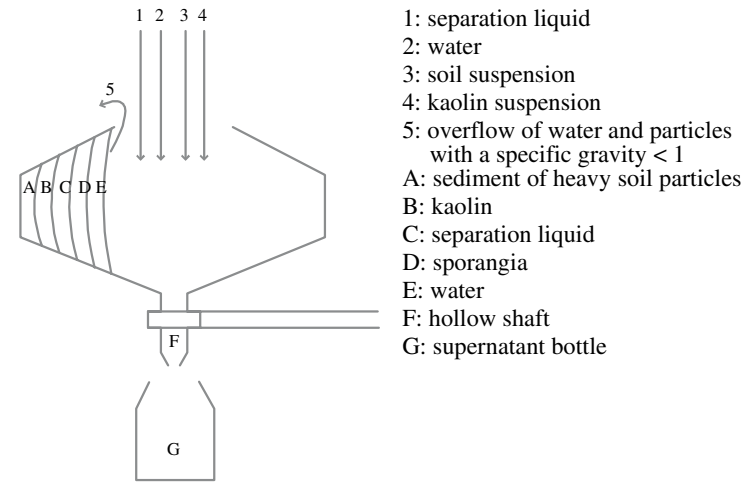

Fig. 1 Side-view of centrifuge rotor with order of injected liquids and order of layers at the end of the centrifuge process. 1: separation liquid; 2: water; 3: soil suspension; 4: kaolin suspension; 5: overflow of water and particles with a specific gravity $<1$; A: sediment of heavy soil particles; B: kaolin; C: separation liquid; D: sporangia; E: water; F: hollow shaft; G: supernatant bottle

an apparatus (HC2-method) built by Instrumentenmakerij de Koning v.o.f., Zierikzee, The Netherlands.

Normally a $\mathrm{CaCl}_{2}$ solution with a specific gravity of 1.4 was used as separation liquid. However, in experiment 3 solutions of $\mathrm{K}_{2} \mathrm{CO}_{3}$ (specific gravity 1.4), colloidal silica gel (specific gravity 1.3) and Nycodenz ${ }^{\circledR}$ (iohexol, specific gravity 1.4 ) were also tested. After centrifugation, the supernatants were additionally rinsed over a $25 \mu \mathrm{m}$ sieve and sporangia were flushed together by rinsing the sieve with saturated $\mathrm{CaCl}_{2}$ solution in experiments 1 and 2 and

Table 1 Overview of materials and methods per experiment

\begin{tabular}{llrlll}
\hline Experiment & Method & Weight soil sample $(\mathrm{g})$ & \% extracted of soil sample & Volume supernatant $^{4}$ & $\mathrm{G} \mathrm{soil}^{5}$ \\
\hline 1 & PPS & 20 & $100 \%$ & 50 & 0.5 \\
2 & HC1 & 100 & $10 \%$ & 42 & 0.3 \\
3 & PPS & 20 & $100 \%$ & 40 & 0.9 \\
& HC1 & 20 & $5 \times 10 \%{ }^{2}$ & 42 & 0.4 \\
4 & PPS & 20 & $100 \%$ & 20 & 20 \\
& HC2 & 200 & $50 \%$ & 20 & 20 \\
\hline
\end{tabular}

\footnotetext{
$12 \times 100 \mathrm{~g}$ for sand + potting soil

2 supernatants were pooled

$35 \times 10 \%$ for clay soil; supernatants were pooled

${ }^{4}$ after additional sieving $(\mathrm{ml})$. For experiments 1 and 2, $2 \mathrm{ml}$ of supernatant were assessed for sporangia while for experiments $3-4$ smaller fractions were assessed as described in the text

$5 \mathrm{~g}$ soil in which theoretically sporangia were counted
} 
with water in experiments 3 and 4 . The supernatants were collected in bottles and stored at $4{ }^{\circ} \mathrm{C}$. This alteration was made after we observed that floating sporangia in a $\mathrm{CaCl}_{2}$ solution started to sink. An overview of soil sample size, percentage extracted of the sample, volume of supernatant and number of readings of sporangia counted $\mathrm{ml}^{-1}$ aliquot for each experiment is given in Table 1. Only a portion of the supernatants were assessed for the presence of sporangia. For samples with low sporangial densities about $20 \%$ of the supernatant volume was assessed, while about $10 \%$ of the supernatants was assessed when spore density was in the mid to high range. Sporangia were counted under a microscope at 100x. In experiments 1 and 2 the floating sporangia in the $\mathrm{CaCl}_{2}$ solution were counted and in experiments 3 and 4 the sunken sporangia in water were counted. The number of sporangia $\mathrm{g}^{-1}$ dry soil (N) was estimated as:

$N=\frac{A \frac{C}{B} \frac{100}{D}}{E F}$

in which:

$\mathrm{A}=$ counted number of sporangia;

$\mathrm{B}=$ volume of supernatant $[\mathrm{ml}]$ used for counting;

$\mathrm{C}=$ total volume of supernatant $[\mathrm{ml}]$;

$\mathrm{D}=$ percentage of suspended soil sample centrifuged;

$\mathrm{E}=$ weight of soil sample $[\mathrm{g}]$;

$\mathrm{F}=$ dry matter content of soil sample.

For experiment 4 the recovery (R) was calculated with the formula:

$R=\frac{A \frac{C}{B} \frac{100}{D}}{G}$

in which:

$\mathrm{G}=$ number of sporangia added to the soil sample.

Soil type

For experiment 1, soil samples of a reclaimed peat soil from Bellingwolde, The Netherlands, infested with $S$. endobioticum, were used. Organic matter content of the soil was $6.6 \%$. For experiment 2, soil samples of a diluvial sandy soil from Horst, The Netherlands, infested with $S$. endobioticum were used. Organic matter content of the soil was $3.9 \%$.
For experiment 3, a diluvial sandy soil from Vredepeel, the Netherlands, was used. Organic matter content of the soil was $3.5 \%$ and $\mathrm{pH}-\mathrm{KCl}$ was 5.5 . Because the soil was also used for a bioassay, high organic matter content was created by adding 41 of potting soil to every 501 soil. For experiment 4 except water, different soil types were used as follows: clay soil from Lelystad (20\% lutum (mineral particles smaller than $2 \mu \mathrm{m}$ ), organic matter $2.6 \%, \mathrm{pH}-\mathrm{KCl} 7.6$ ), sandy reclaimed peat soil from Emmen $(7.7 \%$ loam, organic matter $8.5 \%, \mathrm{pH}-\mathrm{KCl} 5.2)$ and diluvial sandy soil from Veldhoven ( $\mathrm{pH}-\mathrm{KCl} 5.4$ ) with a low (naturally) and a high organic matter content (amended with 5\% $\mathrm{v} / \mathrm{v}$ potting soil).

Clods of clay soil can contain sporangia and therefore have to be suspended. The clay soil subsamples were therefore pre-treated by adding $2 \mathrm{~g}$ disodium oxalate $\left(\mathrm{Na}_{2} \mathrm{C}_{2} \mathrm{O}_{4}\right)$ and water to the $200 \mathrm{~g}$ soil samples. This solution was stored at room temperature for approximately 16 to $20 \mathrm{~h}$ before processing with the HC-method. A preliminary experiment showed that it was difficult to remove clay soil from the centrifuge rotor. To avoid problems, only $10 \%$ of the soil suspension was added into the rotor five times instead of $50 \%$ at once. The supernatants were pooled.

For the Hendrickx centrifuge to operate properly, blocking of the filter on the tube that sucks the soil suspension has to be avoided. Therefore the samples of 'sand + potting soil' in experiment 4 were divided in two sub-samples of $100 \mathrm{~g}$. The supernatants were pooled.

\section{Density series}

In experiments 3 and 4 samples were artificially infested with sporangia of $S$. endobioticum obtained from dry wart compost (decomposed warts in coarse sand) as described by Van Leeuwen et al., (2005). In experiment 3 , a high sporangium density of 625 sporangia $\mathrm{g}^{-1}$ soil was created, with which a dilution series was created. The calculated densities of $0.2,5.1$ and 127 sporangia $\mathrm{g}^{-1}$ dry soil were used.

In experiment 4 , the objective was to create a density series of $0.1,1$ and 10 sporangia $\mathrm{g}^{-1}$ soil. To create the densities for each replicate, a suspension of wart compost inoculum in water 
was made at a density averaging 220 sporangia $\mathrm{ml}^{-1}$ (coefficient of variation of 7\%). By adding a quantity of this suspension with or without dilution to the soil samples, density series of about $0.1,1$ and 10 sporangia $\mathrm{g}^{-1}$ soil were created. Actual densities of sporangia were determined to be 0.15 , $1.16,10.98$ and $0.12,1.10,10.98$, respectively, for the sample series tested by the PPS and $\mathrm{HC} 2$ methods.

\section{Statistics}

Experiments 1, 2 and 4 were carried out with 6 replicates, while experiment 3 was carried out with 4 replicates. For statistical analysis on number of sporangia and recovery percentage the ANOVA statement of GenStat 7 (Payne et al., 2003) was used. In experiment 3, results were analysed after log transformation for which the numbers of counted sporangia were increased by 0.1 because of zeros in the dataset. In experiment 4 results were analysed after square root transformation for which the recovery percentages were added up with 1 because of zeros in the dataset. Coefficients of variation (CV) in experiments 1 and 2 were calculated with the 'Microsoft ${ }^{\circledR}$ Excel 2002' statement STDEV divided with the average number.

For each treatment, in experiment 3 and 4, the counts per soil sample were analyzed with a Generalized Linear Mixed Model (GLMM) (Schall, 1991; Breslow and Clayton, 1993) with link = logarithm and variance proportional to the expected value (quasi likelihood). An offset variable (McCullagh and Nelder, 1989) was used to turn predictions from counts $\mathrm{ml}^{-1}$ to density $\mathrm{g}^{-1}$ soil. With this analysis per object variance between samples $\left(\sigma_{b}^{2}\right)$ and variance between counts within samples $\left(\sigma_{w}^{2}\right)$ was estimated. Usually $\sigma_{w}^{2}$ is called the dispersion. For each treatment, variance for the estimated density per sample was set equal to

$\sigma^{2}=\sigma_{b}^{2}+\frac{\sigma_{w}^{2}}{2}$

In this way counts were adjusted to two counts of $1 \mathrm{ml}$ per soil sample. The logarithm of the estimated variance was used to test differences in precision of the methods. Medians of variances (MV) per method are presented.

\section{Results}

Extraction recovery

As shown in Table 2, recovery of S. endobioticum for the HC-method was better or equal to the PPSmethod. In experiments 1 and 2 the numbers of sporangia were significantly higher for the HC1method (113 and 8 sporangia $\mathrm{g}^{-1}$ soil) compared with the PPS-method (71 and 5 sporangia $\mathrm{g}^{-1}$ soil). In experiment 4 the recovery percentage was $71 \%$ for the HC2-method, significantly higher than the $44 \%$ obtained for the PPS-method. In experiment 3 the number of sporangia did not differ consistently between the HC2- and the PPS-methods. When data were averaged over experiments 1, 2 and 4, the HC-method significantly exceeded the PPS-method by almost $60 \%$. In experiment 3 the tested separation liquids did not significantly affect the extraction recovery (data not shown).

Variation

For experiments 1 and 2 the coefficients of variation (Table 3) could not be statistically tested. In experiment 1 the PPS-method seemed to have a lower coefficient of variation than the HC1-method. No difference was observed in experiment 2. In experiment 3 the tested separation liquids did not significantly affect the MV (data not shown). Also no difference in MV (Table 3) was observed between the PPS-method and the HC2-method when results were restricted to $\mathrm{CaCl}_{2}$ as separation liquid (experiment 3) or to sandy soil (experiment 4). When all separation liquids (experiment 3) and all soil types were involved, (experiment 4), the HC2-method, with MVs of 1.39 and 0.77 performed better than the PPS-method with MVs of 0.46 and 0.62 , respectively. For the HC-method, the MV averaged 50\% lower than for the PPS-method.

Effect of soil type and inoculum density

Table 4 shows the results with different soil types in experiment 4 . The recovery percentage from the sand + potting soil was significantly lower $(36 \%)$ than for sand $(57 \%)$ and reclaimed peat $(61 \%)$. The recovery from clay was intermediate $(52 \%)$. Also, centrifugation without soil gave an intermediate 
Table 2 Number of sporangia detected in or recovered from soil by three different extraction methods

\begin{tabular}{lllll}
\hline Method & \multicolumn{2}{l}{ Number of sporangia } & & \multicolumn{2}{c}{ Recovery } \\
\cline { 2 - 5 } & Experiment 1 & Experiment & Experiment 3 & Experiment $4^{2}$ \\
\hline PPS-method & $70.6 \mathrm{a}$ & $5.25 \mathrm{a}$ & $58.4 \mathrm{a}$ & $44.0 \mathrm{a}$ \\
HC1-method & $113.0 \mathrm{~b}$ & $7.99 \mathrm{~b}$ & $19.9 \mathrm{a}$ & $70.6 \mathrm{~b}$ \\
HC2-method & & & $\mathrm{n} . \mathrm{s}$. & 0.033 \\
F-prob. & $<0.001$ & 0.001 & & \\
LSD & 13 & 1.36 & & \\
\hline
\end{tabular}

For experiments 1-3 data indicate number of sporangia detected, while data for experiment 4 show percent recovery. Data combined from samples with different sporangial densities where appropriate in experiments 3 and 4; extraction methods varied as described in the text.

Data followed by different letters in each column are significantly different at $P>0.05$ (ANOVA)

${ }^{1}$ F-prob. and significant difference based on LSD after log transformation

${ }^{2}$ F-prob. and significant difference based on LSD after square root transformation

Table 3 Coefficients of variation and medians of variances for estimation of sporangial density in soil samples by three different methods

\begin{tabular}{|c|c|c|c|c|c|c|}
\hline \multirow[t]{3}{*}{ Method } & \multicolumn{2}{|l|}{$\mathrm{CV}$} & \multicolumn{4}{|l|}{ MV } \\
\hline & \multirow[t]{2}{*}{ Experiment 1} & \multirow[t]{2}{*}{ Experiment 2} & \multicolumn{2}{|c|}{ Experiment $3^{1}$} & \multicolumn{2}{|c|}{ Experiment $4^{1}$} \\
\hline & & & $\mathrm{CaCl}_{2}^{2}$ & $\mathrm{All}^{3}$ & sand $^{4}$ & $\mathrm{All}^{5}$ \\
\hline PPS-method & 6.9 & 15.6 & $1.27 \mathrm{a}$ & $1.39 \mathrm{~b}$ & $0.67 \mathrm{a}$ & $0.77 \mathrm{~b}$ \\
\hline HC1-method & 11.6 & 15.6 & & & & \\
\hline HC2-method & & & $0.61 \mathrm{a}$ & $0.46 \mathrm{a}$ & $0.56 \mathrm{a}$ & $0.62 \mathrm{a}$ \\
\hline F-prob. & & & n.s. & 0.017 & n.s. & $<0.001$ \\
\hline
\end{tabular}

Data followed by different letters in each column are significantly different at $P>0.05$ (ANOVA)

${ }^{1}$ F-prob. and significant difference based on LSD after log transformation

2 restricted to $\mathrm{CaCl}_{2}$ as separation liquid

3 calculations based on all separation liquids

4 restricted to samples of sandy soil type

5 calculations based on all soil types

recovery (48\%). The MVs of the soil types did not differ significantly and were all significantly better than water.

The number of sporangia counted (actual density in Table 5) in the density series was not affected by the extraction method or the soil type used in experiment 4 . MVs were not affected by the artificially created sporangial density (Table 5), i.e. the recovery and MVs were not lower at lower densities. Also in experiment 3 (Table 6) MVs were not affected within the density range of 1.9 to 86.4 sporangia $\mathrm{g}^{-1}$ soil. So, within the range of 0.087 to 86.4 sporangia $\mathrm{g}^{-1}$ soil the MVs were not affected.

\section{Discussion}

The PPS-method and the HC-method were compared for their ability to extract winter sporangia or sori of $S$. endobioticum from soil. Recovery, accuracy, detection level and labour-intensiveness are important factors in evaluating the utility of the methods. Also it must be possible to extract sporangia from different soil types. Furthermore it is useful when the supernatant can be used for a PCR test and when multiple other organism can be extracted simultaneously.

Based on the results shown in Table 2, it can be concluded that the recovery of the Hendrickx centri- 
Table 4 Average percent of sporangia recovered with the PPS and HC2 methods from different soil types artificially inoculated with sporangia at different densities

\begin{tabular}{lll}
\hline Soil type & Recovery $^{1}$ & $\mathrm{MV}^{2}$ \\
\hline Water & $47.7 \mathrm{ab}$ & $1.22 \mathrm{~b}$ \\
Sand & $57.3 \mathrm{bc}$ & $0.61 \mathrm{a}$ \\
Sand + potting soil & $36.2 \mathrm{a}$ & $0.51 \mathrm{a}$ \\
Reclaimed peat & $60.9 \mathrm{c}$ & $0.71 \mathrm{a}$ \\
Clay & $51.9 \mathrm{abc}$ & $0.58 \mathrm{a}$ \\
F-prob. & $0.042<0.001$ & \\
\hline
\end{tabular}

Data followed by different letters in each column are significantly different at $P>0.05$ (ANOVA)

${ }^{1}$ F-prob. and significant difference based on LSD after square root transformation

${ }^{2}$ F-prob. and significant difference based on LSD after log transformation

Table 5 Target and actual density of sporangia $\mathrm{g}^{-1}$ soil and effect on detection efficacy expressed as medians of variances

\begin{tabular}{lll}
\hline Target density & Actual density & $\mathrm{MV}^{1}$ \\
\hline 0.136 & 0.087 & $0.65 \mathrm{a}$ \\
1.13 & 0.47 & $0.80 \mathrm{a}$ \\
11.0 & 4.2 & $0.63 \mathrm{a}$ \\
F-prob. & & 0.18 \\
\hline
\end{tabular}

${ }^{1}$ F-prob. and significant difference based on LSD after log transformation (Data followed by different letters in each column are significantly different at $P>0.05$ (ANOVA))

Table 6 Effect of actual density of sporangia in soil on detection efficacy expressed as medians of variance

\begin{tabular}{ll}
\hline Sporangium density & $\mathrm{MV}^{1}$ \\
\hline 1.9 & $0.66 \mathrm{a}$ \\
2.0 & $0.55 \mathrm{a}$ \\
86.4 & $0.82 \mathrm{a}$ \\
F-prob. & 0.7 \\
\hline
\end{tabular}

1 F-prob. and significant difference based on LSD after log transformation (Data followed by different letters in each column are significantly different at $P>0.05$ (ANOVA))

fuge is about $60 \%$ better than the recovery of the PPS-method. A possible explanation is given by Chen et al., (2000), who state that with the zonal centrifuge technique, as soil suspension is added gradually into the water layer the nematodes move in the same direction as the heavy soil particles, allowing quick sedimentation of heavy particles including nematodes. In a normal centrifuge this does not occur. It can be expected that $S$. endobioticum sporangia act quite similarly to nematodes during the zonal centrifugation process.

The insignificant lower extraction recovery in experiment 3 of the HC2-method compared to the PPS-method is probably caused by the addition of potting soil. Large organic matter particles might have blocked the filter of the tube that sucks the soil suspension, so that sporangia were trapped. Reduction of sampling size from 200 to $100 \mathrm{~g}$ soil prevented this problem, and was applied in experiment 4 for reclaimed peat soil. In experiment 1 with a reclaimed peat soil the sampling size and the percentage of the sample extracted for the zonal centrifugation were also reduced.

The recovery rates claimed by Pratt (1976) and Laidlaw (1985) are higher ( $80 \%$ to 90\%) than those obtained for the PPS-method or the HC-method in our experiments. The recovery rate of the HC-method was $71 \%$ for the sandy soil in experiment 4 and normally this rate is lower than that obtained by Pratt (1976). Still we prefer the HC-method above the method of OEPP/EPPO which is based on the method of Pratt. This latter method could not be executed without major modifications, it uses complex equipment, dangerous chemicals, and is labour-intensive.

In experiments 3 and 4 the MVs, as a parameter to assess accuracy, were significantly lower for the HC2-method than for the PPS-method. In experiment 3 the soil contamination with different densities was created by dilution of soil amended with a high quantity of wart compost inoculum. In experiment 4 a counted number of $S$. endobioticum sporangia were added to the separate soil samples. So, sample size should not affect measurement error in experiment 3 and certainly not in experiment 4. Also extraction efficiency at the different sporangial densities was not significantly affected by the method used. Therefore, lower MVs must be explained by a better performance of the Hendrickx centrifuge technique.

Furthermore, when soil from infested plots is analyzed, the advantage of the HC-method over the PPS-method, as evident from MVs, must be greater, because the sample size in the former is greater. Starting with the same size of a field-collected soil sample, which is very well mixed, a $20 \mathrm{~g}$ sample for the PPS-method is unlikely to be as representative as a $200 \mathrm{~g}$ sample for the HC2-method 
because the sporangia are not evenly spread throughout the soil.

Counting the sporangia in a higher percentage of the supernatant will improve the MV for both methods equally, but counting at a rate of $2 \mathrm{ml}$ per $20 \mathrm{~min}$ is quite laborious. It has been shown previously that it is possible to detect $S$. endobioticum with a PCR test (Niepold and Stachewicz, 2004; Van den Boogert et al., 2005). This approach was used for supernatants produced in experiments 3 and 4 and is described in Van den Boogert et al., (2005). It is an ideal method for confirming the presence of $S$. endobioticum. Quantification of the PCR reaction with a TaqMan probe is under development (Van den Boogert et al., 2005). This will eliminate the timeconsuming counting procedure, will avoid counting mistakes, and make it possible to process the total supernatant.

The detection levels of the methods differ greatly. When one sporangium is counted in $2 \mathrm{ml}$ out of $20 \mathrm{ml}$ supernatant then 10 sporangia should be found in the total supernatant. This corresponds with 0.5 sporangia $\mathrm{g}^{-1}$ soil for a $20 \mathrm{~g}$ sub-sample used for the PPSmethod and corresponds with only 0.1 sporangia $\mathrm{g}^{-1}$ soil for a $200 \mathrm{~g}$ sub-sample, of which $50 \%$ is analyzed, used for the HC2-method. More subsamples can be readily extracted with the automated Hendrickx centrifuge. After concentrating over the $25 \mu \mathrm{m}$ sieve, the laborious counting is not increased, while the detection level decreases to 0.02 sporangia $\mathrm{g}^{-1}$ soil when 5 sub-samples of $200 \mathrm{~g}$ are extracted. So, the current level for partial de-scheduling an infested plot with no more than five sporangia $\mathrm{g}^{-1}$ soil (OEPP/EPPO, 1999) is easily met by both methods. However, this threshold does not seem to be appropriate (Baayen et al., 2005), because infection is possible at much lower densities of about 0.1 sporangia $\mathrm{g}^{-1}$ soil (Hampson, 1992; Browning, 1995; Baayen et al., 2005). Therefore a lower threshold level is necessary and is within reach, especially for the HC2-method, with an acceptable measurement error.

The coefficient of variation of a method depends, amongst others, on factors that can be changed easily, such as using a larger quantity of the field-collected soil samples and increasing the quantity of supernatant used for counting spores. Using a larger quantity of soil with the PPS-method makes the method much more laborious. From sub-sampling $20 \mathrm{~g}$ of the original soil sample, centrifuging, concentrating via a $25 \mu \mathrm{m}$ sieve, cleaning of centrifuge tubes, the total process takes about $55 \mathrm{~min}$ when five other samples are processed simultaneously. Processing extra samples will take about 35 min per sample. With the Hendrickx centrifuge, when several samples are processed successively, the total process takes one person about $30 \mathrm{~min}$ for one $200 \mathrm{~g}$ sample. Processing extra samples takes about $10 \mathrm{~min}$ per sample. So, the Hendrickx centrifuge is less laborious than the PPS-method, especially when more samples per fieldcollected soil sample are processed. Nevertheless, the PPS-method is a less laborious method than the officially prescribed method (OEPP/EPPO, 1999).

During the second centrifugation step of the PPSmethod and subsequently in the supernatant, the organisms are exposed to the osmotic pressure caused by the $\mathrm{CaCl}_{2}$ solution (Chen et al., 2000). Extracted organisms might be affected by this process. For $S$. endobioticum we observed a decrease in the number of floating sporangia during storage in a $\mathrm{CaCl}_{2}$ solution. During the centrifugation process of the HC-method the $S$. endobioticum sporangia are collected at the interface of water $-\mathrm{CaCl}_{2}$ layer where the osmotic pressure is lower than in a $\mathrm{CaCl}_{2}$ solution. Afterwards in the supernatant the osmotic pressure is absent, because the specific gravity of the supernatant is only about 1.02. In experiment 3 extraction recovery and MVs of the HC2-method was not significantly affected by the separation liquids $\mathrm{CaCl}_{2}, \mathrm{~K}_{2} \mathrm{CO}_{3}$, colloidal silica gel and Nycodenz ${ }^{\circledR}$ indicating that a lower osmotic pressure and a lower specific gravity than the one from $\mathrm{CaCl}_{2}$ did not affect recovery efficiency. From our own observations we know that the specific gravity of intact sporangia of $S$. endobioticum varies between 1.15 and 1.35, with $85 \%$ below or equal to 1.3 (Wanten, 2000, pers. comm.). Glynne (1926) calculated the specific gravity of sporangia to be 1.175 , based on falling rate in water and the diameter. Probably a specific gravity of 1.3 of a separation liquid is high enough to 'catch' most of the sporangia of $S$. endobioticum.

With the Hendrickx centrifuge a low extraction recovery was found for samples of sandy soil with an addition of potting soil. However, a reclaimed peat soil showed a high recovery probably due to a reduced sample size. Therefore, based on experiment 4 it can be concluded that most soil types can be handled with the HC2-method. 
The Hendrickx centrifuge was developed to extract free-living nematodes from soil (Hendrickx, 1995; Chen et al., 2000). Results described in our study clearly indicate that the method can also be used to adequately extract sporangia of S. endobioticum into a supernatant in which the number of sporangia of $S$. endobioticum can be counted. Based on the principle of the Hendrickx centrifuge, it can be predicted that all small particles with a specific gravity heavier than water and lower than the separation liquid (e.g. fungal resting spores, nematodes) and which can withstand the high g-force, can be extracted from soil samples with this method. With the combination of PCR, soil samples can be analyzed to detect several organisms in a multiplex procedure, even when the organisms cannot withstand the high g-force.

Chen (et al., 2000) showed good results with HC1 for Meloidogyne chitwoodi. Preliminary results with HC2 show that the method might be used for extraction of Pratylenchus penetrans nematodes (van Beers, 2004, pers. comm.) and for Verticillium dahliae sclerotia (Bonants and van den Boogert, 2004, pers. comm.).

After extraction of the winter sporangia from soil, the supernatants of experiments 3 and 4 were used for DNA extraction. DNA samples were further used in a PCR test to detect $S$. endobioticum. According to the results, which were recently presented (Van den Boogert et al., 2005), the real-time PCR assay could be used to detect and quantify S. endobioticum in HCextracts in samples with sporangial densities of 0.05 or more per $1 \mathrm{~g}$.

In conclusion, we found that the PPS-method performs better than the recommended EPPOmethod (OEPP/EPPO, 1999) which failed to function without major modifications (Van Leeuwen et al., 2005). With these modifications the EPPO method resulted in a greater recovery compared with the PPS method. However, the Hendrickx centrifuge method performs better than the PPS-method. This conclusion is based on a better recovery, lower MVs, and a lower detection level. Furthermore, the Hendrickx centrifuge method is less laborious and overcomes the osmotic pressure problem caused by the saturated $\mathrm{CaCl}_{2}$ solution as separation liquid. Both methods are suitable for different soil types and the supernatant can be used for a PCR-test. Therefore, the Hendrickx centrifuge technique might be a good tool for adoption within the official EPPO procedures.

Acknowledgements The authors wish to thank the Dutch Ministry of Agriculture, Nature and Food Quality, and the Dutch Plant Protection Service for financial support. For carrying out the experiments we are grateful to J.W. Meijer and A.M. Ramaker of Applied Plant Research, M. van Gent-Pelzer of Plant Research International and J.P. Meffert of Plant Protection Service. We also thank R.P. Baayen, formerly of Plant Protection Service for technical advices.

\section{References}

Baayen, R. P., Bonthuis, H., Withagen. J. C. M., Wander, J. G. N., Lamers, J. L., Meffert, J. P., Cochius, G., Van Leeuwen, G. C. M., Hendriks, H., Heerink, B. G. J., Van den Boogert, P. H. J. F., Van de Griend, P., \& Bosch, R. A. (2005). Resistance of potato cultivars to Synchytrium endobioticum in field and laboratory tests, risk of secondary infection, and implications for phytosanitary regulations. EPPO Bulletin, 35, 9-23.

Baayen, R. P., Cochius, G., Hendriks, H., Meffert, J. P., Bakker, J., Bekker, M., Van den Boogert, P. H. J. F., Stachewicz, H., \& Van Leeuwen, G. C. M. (2006). History of potato wart disease in Europe, a proposal for harmonisation in defining pathotypes. European Journal of Plant Pathology, 116, 21-31.

Breslow, N. E., \& Clayton, D. G. (1993). Approximate inference in generalized linear mixed models. 88 (421), 9-25. Journal of the American Statistical Association, 88, 9-25.

Browning, I. A. (1995). A comparison of laboratory and field reactions of a range of potato cultivars to infection with Synchytrium endobioticum (Schilb.) Perc. Potato Research, 38, 281-289.

Chen, S., Hendrickx, G., \& Moens, M. (2000). The importance of organic matter when assaying Meloidogyne chitwoodi soil populations. Russian Journal of Nematology, 8, 147-152.

EU (2000) Council Directive 2000/28 on protective measures against the introduction into the Community of organisms harmful to plants or plant products and against their spread within the community. Official Journal of the European Communities, no. L169, 1-112.

Glynne, M. D. (1926). The viability of the winter sporangium of Synchytrium endobioticum (Schilb.) Perc., the organism causing wart disease. Annals of Applied Biology, 13, 19-36.

Hampson, M. C. (1979). Research on potato wart disease in the USSR - a literature review (1955-1977). Canadian Plant Disease Survey, 59, 7-14.

Hampson, M. C. (1989). Potato wart disease in Newfoundland: a review of current research studies. Bulletin OEPP/ EPPO Bulletin, 19, 425-429.

Hampson, M. C. (1992). A bioassay for Synchytrium endobioticum using micropropagated potato plantlets. Canadian Journal of Plant Pathology, 14, 289-292.

Hampson, M. C., Porter, G. M., Morris, P. J., \& McRae, K. B. (1983). Identification of field loci with potential for 
biological control of the potato wart disease. Canadian Journal of Plant Pathology, 5, 43-48.

Hendrickx, G. (1995). An automatic apparatus for extracting free-living nematode stages from soil. Nematologica, 41, 308.

Laidlaw, W. M. R. (1985). A method for the detection of the resting sporangia of potato wart disease (Synchytrium endobioticum) in the soil of old outbreak sites. Potato Research, 28, 223-232.

McCullagh, P., \& Nelder, J. A. (1989). Generalized Linear Models, Second Edition. London: Chapman and Hall.

Niepold, F., \& Stachewicz, H. (2004). PCR-detection of Synchytrium endobioticum (Schilb.) Perc. Zeitschrift für Pflanzenkrankheiten und Pflanzenschutz, 111, 313-321.

OEPP/EPPO (1999) Synchytrium endobioticum: soil tests and descheduling of previously infested plots. Phytosanitary Procedure PM 3/59(1). OEPP/EPPO Bulletin 29, 225231.

Payne, R., Baird, D. B., Cherry, M., Gilmour, A. R., Harding, S. A., Kane, A. F., Lane, P. W., Murray, D. A., Soutar, D. M., Thompson, R., Todd, A. D., Tunnicliffe Wilson, G., Webster, R., \& Welham, S. J. (2003). GenStat $\AA$ for WindowsTM, 7th edn. Oxford, UK: VSN International.

Pratt, M. A. (1976). A wet-sieving and flotation technique for the detection of resting sporangia of Synchytrium endobioticum in soil. Annals of Applied Biology, 82, 21-29.

Schall, R. (1991). Estimation in generalized linear models with random effects. Biometrika, 78, 719-727.
Singh, P. H., \& Garg, I. D. (2003). Wart disease of potato in India - present scenario. Journal of the Indian Potato Association, 30, 3-4.

Stachewicz, H. (2004). Nachweis von Dauersporangien des Kartoffelkrebserregers Synchytrium endobioticum (Schilb.) Perc. durch die direkte mikroskopische Bodenuntersuchung. Nachrichtenbl Deut Pflanzenschutzd, 56, 62.

Van den Boogert, P. H. J. F., Van Gent-Pelzer, M. P. E., Bonants, P., De Boer, S. H., Wander, J. G. N., Lévesque, C. A., Van Leeuwen, G. C. M., \& Baayen, R. P. (2005). Development of PCR-based detection methods for the quarantine phytopathogen Synchytrium endobioticum, causal agent of potato wart disease. European Journal of Plant Pathology, 113, 47-57.

Van Leeuwen, G. C. M., Wander, J. G. N., Lamers, J., Meffert, J. P., Van den Boogert, P. H. J. F., \& Baayen, R. P. (2005). Direct examination of soil for sporangia of Synchytrium endobioticum using chloroform, calcium chloride and zinc sulphate as extraction reagents. EPPO Bulletin, 35, 25-31.

Vasyutin, A. S., Smetnik, A. I. (1999). Modern scientific problems of plant quarantine in the Russian Federation. Zashchita i Karantin Rastenii, 11, 27-29.

Zelya, A. G., \& Melnik, P. A. (1998). Detection methods for Synchytrium endobioticum. EPPO Bulletin, 28, 543-544. 